\title{
Does Assertive Community Treatment Work with Forensic Populations? Review and Recommendations
}

\author{
Jerry L. Jennings*
}

Liberty Healthcare Corporation, PA 19004, USA

\begin{abstract}
Several variations of the Assertive Community Treatment model have been tried with forensic and offender populations, including Forensic Assertive Community Treatment (FACT), Forensic Intensive Case Management (FICM) and Integrated Dual Diagnosis Treatment (IDDT). Based on a comprehensive review of multiple reviews and research studies, it appears that the field is converging on the conclusion that ACT may have a positive impact on mental health for forensic patients, but that it is probably ineffective or minimally effective in reducing criminal recidivism. The author argues that emerging research from the "forensic continuum of care model" and correctional re-entry treatment programs suggests that the community aftercare component is vital with offending populations and that aftercare programs like ACT can be enhanced by a "pre-treatment" residential treatment precursor. Specifically, the provision of enriched or extended residential treatment - in which forensic patients have adequate time to learn, practice and master life management skills - can maximize the effectiveness of follow-up ACT. Most FACT and FICM approaches have lacked this "continuum" feature.
\end{abstract}

\section{THE DEVELOPMENT AND WIDESPREAD ACCEPT- ANCE OF ACT}

Assertive Community Treatment (ACT) first developed in the early 1970 s as one of many initiatives to address the federal mandate for shifting the locus of care from institutions to the community. In just ten years, the state hospital population in the United States declined by $80 \%$ with more than 400,000 state hospital patients being discharged from 1965 to 1975 . The impact of deinstitutionalization was profound and revolutionized public mental health. Great numbers of psychiatric patients were readmitted to state hospitals after relapsing into psychosis; others floundered in ill-prepared community programs; and the least fortunate became homeless or were incarcerated. The challenges of mass deinstitutionalization forced many clinicians and researchers to innovate with new community-based methods of restoring and maintaining mental health for persons with serious and persistent mental illness [1]. Efforts to "extend" the intensive supports of the inpatient setting included partial hospitalization, outpatient programs with intensive case management and Assertive Community Treatment.

The team of Stein, Test, and Marx at the Mendota Mental Health Institute in Madison, Wisconsin are credited with the creation of the ACT model, which received a Gold Award as early as 1974 under the name "community treatment" [2-4]. Originating in their work with persons with chronic schizophrenia, the ACT model is another historic example of how innovations in the treatment of schizophrenia have decisively changed fundamental approaches in mental health

*Address correspondence to this author at Liberty Healthcare Corporation, 401 E. City Ave., Suite 820, Bala Cynwyd, PA 19004, USA; Tel: 610-6688800; Fax: 610-667-5559; E-mail: jerryj@libertyhealth.com treatment [5]. The essential ACT model calls for a "total team approach" by an interdisciplinary team (typically consisting of a psychiatrist, psychiatric nurse, social worker and/or other mental health professional), who are dedicated to closely monitoring and supporting a specific, small caseload of persons with severe mental illness in real life community settings. Since ACT provides intensive aroundthe-clock assistance, it is a labor intensive methodology and is therefore usually reserved for individuals with the most severe and persistent psychiatric disorders, who are at greatest risk for homelessness and re-hospitalization [1, 6-8].

Over the years, there have been variations in the basic ACT model, such as "family-aided ACT" [9], "ACT with supported employment" [10], and ACT with substance abuse treatment for dual diagnosed populations [11]. In all of its variations, the essential ACT model focuses on vigorous outreach by a single integrated team to deliver services, supports, and rehabilitation that enable even the most disabled persons to maintain a decent quality of life in the community.

As of 1998, the ACT methodology had already been tested in at least twenty-five randomized controlled trials and reviewed in numerous articles [12]. In a special journal issue that focused on ACT, Essock, Drake \& Burns [13] affirmed that:

Since the deinstitutionalization era began nearly fifty years ago, several models of communitybased care for persons with severe mental illnesses have been developed. Of these models, the assertive community treatment (ACT) program has by far the strongest empirical support. 
ACT has been endorsed as an effective evidence-based treatment by the Robert Wood Foundation and the Substance Abuse and Mental Health Services Administration [14]. In one very large, randomized controlled trial over ten sites [15, 16], researchers concluded that ACT consistently achieved "reduced hospital use, cost savings, greater consumer satisfaction, and, in the long term, less severe symptoms and better community functioning" [17]. Similarly, a continuum of residential treatment and ACT was recognized as a best practice model by the American Psychological Association's (APA) Committee for the Advancement of Professional Practice's (CAPP) Task Force on Serious Mental Illness and Severe Emotional Disturbance [18].

At the same time, Gomory [19] has contested the claim that ACT is a well-tested, evidence-based treatment by arguing that there is a lack of controlled experimental research. Gomory and others have criticized ACT for being intrusive, coercive and paternalistic, claiming that it is antithetical to the ultimate goals of independence and selfdetermination [20]. As a methodology, ACT has been accused of trying "to 'do' for the client what the client could not do for himself or herself" [21] or, in the words of another critic, "You can be case managed to death" [22]. ACT has also been criticized for its over-reliance on psychiatric medication as the foundation of treatment, estimating that "almost 50 per cent of ACT client contact time is spent dispensing and managing psychotropic medication" [23]. Such critics warn against the well-known adverse effects of antipsychotic medications and coerced medication compliance [22].

Another criticism of Assertive Community Treatment is that it fails to "rehabilitate" individuals with serious and persistent mental illness. Thus, the person could need ACT for years to come, or even a lifetime. The counterargument is that full ACT should only be necessary during the initial period of community reintegration when the individual is in need of the most intensive support and then resources can be gradually reduced in intensity. Ideally, as the individual becomes increasingly grounded in his/her community life (e.g., steady employment, housing, daily routines, natural supports, etc.), he/she becomes more independent and selfsufficient.

These critiques notwithstanding, ACT has clearly established itself as effective in reducing hospitalization and promoting community tenure. As of 2003, over 360 articles could be found in PsycINFO database on ACT [19]. ACT may be the most widely studied psychosocial treatment intervention for persons with serious and persistent mental illness. In their comprehensive review, the Lewin Group [24] concluded that the best outcomes were achieved only when all of the critical elements of the ACT model are delivered in combination. More recently, Coldwell and Bender [25] performed a meta-analysis of fifty-two ACT studies, which continues to affirm that ACT is superior to standard case management in maintaining mental health and reducing homelessness for homeless persons with serious and persistent mental illness.

\section{ACT APPLIED TO FORENSIC POPULATIONS}

Given the national trend in which jails and prisons have increasingly supplanted state hospitals as the main provider of psychiatric services for persons with severe mental illness, there have been increasing efforts to apply ACT to forensic populations. Here too, traditional "high fidelity" ACT has shown effectiveness in improving psychiatric stabilization, but outcomes have been weaker in terms of re-arrest and days of incarceration. In a review of 40 controlled studies, Bond, Drake, Mueser \& Latimer [26] found that ACT was most effective in reducing use and number of days in the hospital, moderately effective in improving psychiatric symptoms, but ineffective or only minimally effective in reducing arrests/jail time, reducing substance abuse or improving social adjustment and quality of life.

The movement to apply ACT to forensic and criminal justice populations in the 1990's gave rise to a variety of "forensic ACT" (FACT) and "forensic intensive case management" (FICM) approaches. This proliferation of FACT and FICM models, however, introduced greater variability to the traditional Assertive Community Treatment model:

\begin{abstract}
The concept of FACT has disseminated more rapidly than the actual practice of using a highfidelity ACT team with criminal justice populations. FACT teams often operated from an "ACT-lite" perspective that strips away some of the high-fidelity elements (such as 24/7 availability, daily team meetings, employment specialists) and adds new elements not found in typical ACT teams (such as a probation, parole, or police officer) [27, p. 533].
\end{abstract}

In recognition of this diversity of applications, Lamberti, Weisman and Faden [6] attempted to restrict the definition of "FACT" to those programs that (1) specifically serve persons with severe mental illness and histories of arrest and incarceration; (2) whose primary source of referrals is the criminal justice system; and (3) are closely coordinated with the criminal justice system. Lamberti, et al. [6] identified a total of sixteen FACT programs, seven of which provided some type of supervised residential component (of which five specifically provided residential addictions treatment). The high number of residential programs is notable because residential rehabilitation is not a component in the classic ACT model [8].

Only three of the FACT programs in Lamberti's national review had published outcome data in professional journals: the Arkansas Partnership Program [28]; Project Link in Rochester, New York [29, 30]; and the Thresholds Jail Project in Chicago [31, 32]. Both Project Link and the Thresholds Project achieved reductions in both jail days and hospital days, but neither study reported on mental health or quality of life outcomes. The Arkansas Partnership Program achieved positive outcomes in both criminal recidivism and mental health outcomes, but it failed to include a controlled comparison. This pilot study released 18 forensic patients into ACT and achieved an average of 508 days without 
rearrest or substance abuse and only $17 \%$ were readmitted to inpatient or residential care [28].

Based on their review, Lamberti, et al. [6, p. 1286] concluded that traditional ACT programs can reduce hospitalization and lengthen community tenure, but "have shown little or no effect in reducing criminal recidivism" [26]. It was acknowledged that a few ACT programs in the criminal justice sector, such as Project Link, have published reports of reduced arrest and incarceration, but the validity of the results were questioned because "most of the studies have been naturalistic and were conducted without comparison groups or randomization" [6, p. 1286].

Given the relatively high cost of ACT, others have tried to use Intensive Case Management with persons with forensic issues (FICM). Unlike FACT, the FICM approaches do not have a designated team nor 24/7 support, and psychiatric services are brokered with a community provider. The best evidence for FICM comes from the SAMHSA jail diversion study [33, 34], which reduced jail outcomes but had minimal or no effect in improving mental health. In contrast, a California study of FICM [35] and a Philadelphiabased study of both FACT and FICM [20,36] failed to show any improvements in jail outcomes. In fact, the Philadelphia study found that the FACT group had the highest recidivism rate of $56 \%$ compared to $22 \%$ for the FICM group and $36 \%$ for the no-intervention control group. It was suggested that adding a probation officer to the FACT team increased the likelihood of having criminal activities detected, thus inflating the rate of rearrest.

More recently, Loveland and Boyle [37] compared three types of Intensive Case Management for forensic patients with serious and persistent mental illness: General ICM programs; general ICM with an integrated addictions treatment component; and ICM programs that were part of a jail diversion intervention. Based on their review of the ICM research literature, Loveland and Boyle concluded that general ICM programs failed to reduce jail or arrest rates, while general ICM with addiction treatment had mixed results, with a slight trend toward reducing criminal recidivism for the dually diagnosed. The jail diversion ICM programs also had mixed results, but most achieved "significant reductions in arrests and incarcerations over time." Time periods varied across ICM studies.

Recognizing the frequency of substance abuse disorders in those with severe mental illness, others have modified ACT to create "integrated dual diagnosis treatment teams" or IDDT $[38,39]$. In a study of 144 homeless persons with severe mental illness and addictions, Calsyn, Yonker, Lemming, Morse and Klinkenberg [39] found that IDDT improved substance abuse outcomes and reduced hospitalizations, but did not reduce criminal recidivism. Since $52 \%$ were arrested and $26 \%$ reincarcerated within a two year period, Caslyn, et al. [39] suggested that the ACT model needed something extra to also reduce criminal behavior.

In a more recent review, Morrissey, Meyer and Cuddeback [27] concluded that there is weak and inconsistent evidence that either FACT or FICM are effective in preventing criminal recidivism. They assert that only two studies have tested FACT in a controlled fashion: Project Link [29] and the Thresholds Collaborative Jail Linkage project [30]. In both cases, FACT achieved reductions in both jail days and hospital days, but neither study reported on mental health or quality of life issues. Morrissey et al. [27] ultimately concluded that application of even the most rigorous ACT model to forensic populations is not enough to reduce criminal recidivism and that FACT and FICM have, to date, failed to produce consistent results. Instead they recommended more effort in designing a specific ACT model for the subset of persons with psychiatric disabilities and criminal justice involvement. They pointed to "specialized cognitive behavioral therapy" [40], modified therapeutic communities [41, 42] and drug courts [43] as encouraging models for future study.

\section{FORENSIC CONTINUUM MODELS}

Based on the multiple reviews and research studies described above, it would appear that traditional Assertive Community Treatment (ACT), Forensic ACT (FACT), Forensic Intensive Case Management (FICM) and Integrated Dual Diagnosis Treatment (IDDT) may positively impact mental health for forensic psychiatric patients, but they are generally ineffective in preventing criminal recidivism. For example, Bond, Drake, Muesar and Latimer [26] reported a $20 \%$ rearrest rate for ACT with non-forensic populations; Solomon and Draine $[19,36]$ reported a $22 \%$ rearrest rate for FICM and 56\% for FACT; while Calsyn, et al. [39] reported a $52 \%$ rearrest rate and $26 \%$ reincarceration rate using IDDT. In two authoritative reviews of Forensic ACT by Morrissey, et al. [27] and Lamberti, et al. [6], researchers have concluded that there is weak or inconclusive evidence that FACT, FICM or IDDT are effective in preventing criminal recidivism.

A recent empirical study, however, seriously challenges this pessimistic conclusion and may help explain the mixed and disappointing results that have been observed in other FACT and FICM studies. After publishing the initial excellent results achieved using their "forensic continuum" model, the Arkansas Partnership Program (APP) continued to measure long-term outcomes for an expanded group of forensic patients receiving ACT $[28,44,45]$. In an uncontrolled follow-up study of high-risk forensic patients with serious and persistent mental illness and chemical dependency, the APP achieved consistently high rates of psychiatric health, substance abuse abstinence, stable housing, and meaningful activity over a nine year period while also preventing criminal recidivism [45]. Out of a total of 91 high-risk forensic patients, only eight (9\%) were readmitted to the state hospital, while only five patients $(5 \%)$ were re-arrested and one (1\%) was reincarcerated.

With a long-term rearrest rate of just 5\% over many years, the Arkansas Partnership Program (APP) clearly set a benchmark for preventing criminal recidivism in addition to improving behavioral health across multiple dimensions. As shown in Fig. (1) below, APP achieved far superior outcomes in reducing criminal recidivism than all of the other approaches to using ACT with forensic populations. 


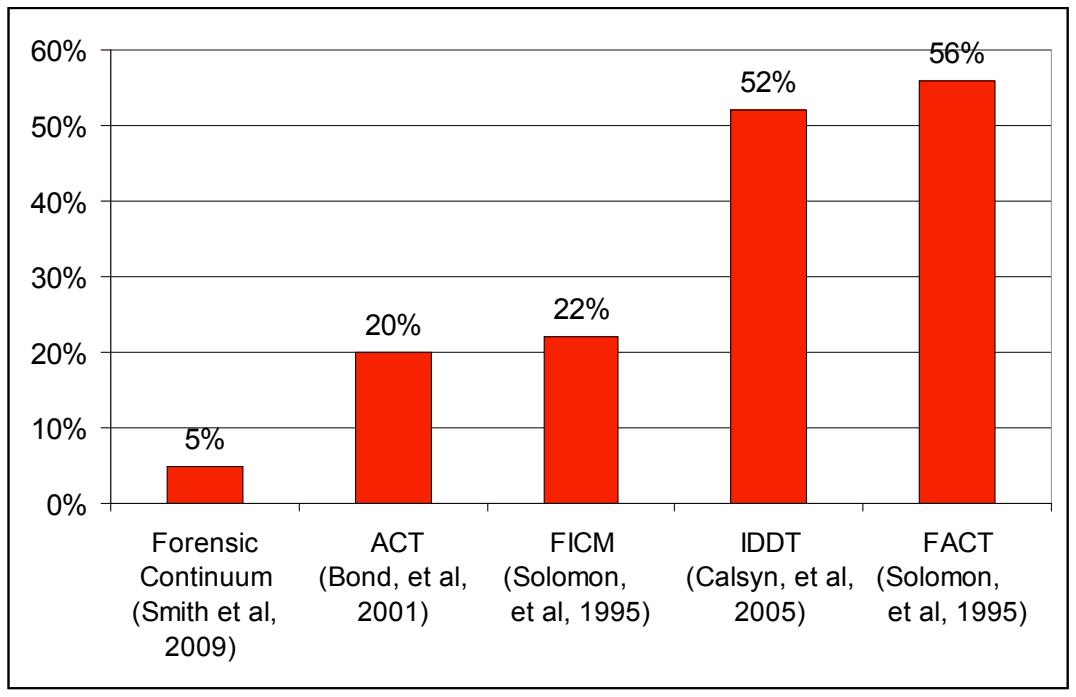

Fig. (1). Rate of rearrest observed across forensic approaches.

A closer examination of the APP model may provide insights into the question of whether FACT is effective with forensic patients and help to explain the mixed and discouraging results obtained from similar FACT programs. Most importantly, the APP carefully retained the fidelity of the traditional ACT model with its intensive 24/7 availability and daily team meetings. The ACT team at APP was comprised of a psychiatrist, psychologist, social worker, substance abuse counselor, recreation therapist, nurse and counseling assistant. As such, the APP program can be fairly compared to other ACT programs for forensic populations.

At the same time, the APP was distinctive because it provided an enriched residential rehabilitation program with integrated dual diagnosis treatment as a precursor to Assertive Community Treatment. In other words, the APP bridged the traditional gap between the state inpatient hospital and ACT aftercare by providing an extended secure residential treatment program in which the participants could learn and practice life management skills prior to release into ACT. The residential component of the APP was described as a "stage progressive recovery model" in which the patients could gradually build the life skills, coping skills, and community supports that they needed to make a successful transition to independence and stability. There was also on-going interaction between the residential clinical staff and the community-based aftercare case managers, who frequently visited their assigned patients in the secure residential facility. Thus, by the time a patient had attained the skills and knowledge of the final program level, he/she had a close working relationship with his/her aftercare case manager and had begun the transition to community life, including supervised excursions to find housing, employment and other services.

One distinguishing feature of the APP model, which limits its comparability to other forensic ACT programs, may be its extended length of treatment. The participants averaged 320 days of inpatient treatment followed by an average of 861 days of residential rehabilitation before entering ACT. The authors justified the long length of treatment by pointing to the profound clinical severity and risk level of the population served. All patients were adjudicated Not Guilty by Reason of Insanity with severe, long-standing psychiatric disabilities and co-occurring chemical dependency as well as histories of violence that rendered them too dangerous to be released from the state forensic hospital. Two case examples attest to the level of risk and clinical dysfunction of those served in the APP [46]:

Case example 1: "Joe" was diagnosed with manic psychosis and severe cocaine addiction and had been institutionalized or in trouble with the law for most of his life. He had eighteen psychiatric admissions to the state hospital, with multiple elopements and escapes. His extensive arrest record included armed robbery, 1st and 2nd degree battery, weapon and drug possession, thefts, disorderly conduct, resisting arrest and assault on a police officer. At the time of admission to APP, Joe had been securely confined for eight consecutive years in the state forensic unit and displayed irritable, impulsive and aggressive behavior. Outcome: Joe achieved and maintained steady full-time employment and became a responsible father to a large family. At last measure, he had maintained sobriety for eight years and was entirely free of public assistance and entitlement monies.

Case example 2: "Hank" was diagnosed with severe paranoid schizophrenia and was virtually mute. His pervasive delusions and cognitive deficits shaped him into a hostile and aggressive "loner," alienated from family and society. Hank began heavy drinking as a teenager and moved into abuse of cocaine, marijuana and pills as his psychiatric disability worsened. His long criminal history included fighting, property destruction, robbery, burglary, drug dealing and drunk driving. At the time of admission to APP, Hank had been "stuck" for twenty-five years, 
living as a social outcast whose only source of pleasure came from drugs. Outcome: Hank became a sociable and well-liked citizen, who restored a good relationship with his family and developed many friendships. He remained sober for years, living alone in an apartment while maintaining part-time employment.

Considering the remarkable results achieved with such profoundly challenged, high-risk forensic patients, the APP "forensic continuum of care" offers compelling evidence of what can be achieved with Assertive Community Treatment in the context of a well-conceived program with ample resources. In nine years, the APP restored dozens of individuals, who had been previously considered "untreatable" and "too dangerous" to release and would have otherwise spent their lives in the forensic units of a state psychiatric hospital.

On the other hand, the Arkansas Partnership Program can be criticized for a number of issues. First, and foremost, the APP study did not use a randomized control group to actually prove its effectiveness. Second, the APP model required resources that are extremely costly and unrealistic for many public mental health programs. Although the forensic continuum of care was much cheaper than traditional inpatient hospitalization of indefinite duration, it was more expensive than ACT alone. Nonetheless, mental health authorities and policy makers need to understand that the enduring rehabilitation of an extremely challenging population will necessarily require more resources up front, but that an effective program will achieve more cost savings in the long run by maximizing independence and selfsufficiency.

Finally, critics could argue that it is not fair to directly compare outcomes for programs providing forensic ACT alone with this program providing a residential treatment precursor to forensic ACT. In this regard, however, it is notable that $44 \%$ of the sixteen forensic ACT studies reviewed by Lamberti, et al. [6] also included supervised residential treatment prior to ACT.

Despite these issues, the overwhelmingly positive results from the Arkansas Partnership Program strongly support the need for continued experimentation using ACT with forensic and offender populations. At a point where the field appears to be converging on the pessimistic conclusion that forensic ACT is ineffective or minimally effective in reducing criminal recidivism, the APP study presents extraordinary evidence to the contrary. In particular, it appears that the continuum feature of the APP model (that is, the extended period of residential rehabilitation that enables patients to learn and practice life management skills) can maximize the effectiveness of traditional Assertive Community Treatment. Most other FACT and FICM approaches have lacked this continuum feature.

\section{CORRECTIONAL REENTRY TREATMENT PROGRAMS}

The emerging research on correctional reentry programs also offers empirical support for the importance of rehabilitative residential "pre-treatment" prior to entering aftercare. Reentry programs share some illuminating similarities to the "continuum of care" model of ACT. As an approach, reentry programs typically address a common array of issues for addicted offenders, such as job skill development, employment support, housing assistance, guidance, life skills training, mentoring, and mental health and substance abuse treatment. Optimally, reentry programs entail three distinguishable phases: (1) a prison-based Therapeutic Community program which prepares inmates for reentry; (2) a community-based transitional program that assists offenders just prior to and immediately following release; and (3) longer-term, community-based aftercare support and treatment [47, 48]. A number of large-scale research studies have compared outcomes for offenders receiving some, all or none of these three reentry components, which roughly correspond to the continuum of inpatient and/or residential treatment followed by ACT aftercare.

Like ACT, research has consistently shown that the best reentry outcomes are achieved when in-facility treatment is followed by post-release aftercare treatment [49]. In particular, the most successful research-based programs have combined intensive in-prison substance abuse treatment using the Therapeutic Community (TC) model with transitional and aftercare support. In California, offenders who completed the Amity Prison TC and its Vista Aftercare Program averaged 51 fewer days incarcerated (36\% less) than those receiving no treatment $[50,51]$. Similarly, in Texas, researchers found that only $25 \%$ of those who completed in-prison TC treatment and community aftercare were reincarcerated compared to $64 \%$ of the aftercare dropouts and $42 \%$ of untreated prisoners [52].

In Delaware, a six-month Therapeutic Community (TC) work release and aftercare program reduced reincarceration by an average of 30 fewer days (29\% less) than a standard work release program, while the aftercare component reduced reincarceration by an average of 49 fewer days (43\% less) compared to work release-only. Subsequent evaluation of the Delaware program reaffirmed that the each of the three reentry components - in-prison, transitional and aftercare treatment - had beneficial effects, but concluded that the transitional residential program had a significantly larger and more long-lasting impact [53]. The same research team evaluated five year outcomes for 1,122 participants and found that treatment during work release halved relapse, while treatment before or during prison did not have a significant impact [54]. They found that $52 \%$ of those who received work release $\mathrm{TC}$ and aftercare were rearrested compared to $58 \%$ receiving work release TC only and $77 \%$ of those receiving standard work release.

When other researchers combined a sample of 1,461 inmates from the California, Texas and Delaware reentry programs, they found that about $25 \%$ of those receiving intensive drug treatment and aftercare were reincarcerated compared to $75 \%$ for those receiving no treatment or inprison treatment alone [55]. In Bermuda, researchers found that full completion of rehabilitative treatment with parole aftercare reduced reincarceration to just $13 \%$ over a seven 
year period [56]. This outcome was four times more effective than partial rehabilitative treatment without parole aftercare (51\%). By comparison, 58\% of those who dropped out of reentry treatment and an estimated $78 \%$ for those receiving no treatment were reincarcerated.

\section{SUMMARY AND CONCLUSIONS}

In conclusion, most research on Assertive Community Treatment with forensic populations has shown mixed, negative and inconclusive results. It is reasonable to argue that these inconclusive results may derive from the great variability of ACT-related treatment models that have been used to date, which include FACT, FICM, IDDT and forensic continuum models. To the degree that these differing programs and approaches have adhered to the fidelity of the ACT model, it is difficult to make direct comparisons of outcomes across programs. Moreover, the level of success of forensic community treatment may also be impacted by the diversity of other factors such as setting (e.g., jail, prison, forensic hospital); diagnosis (e.g., schizophrenia, bipolar, schizoaffective, chemical dependency); choice (e.g., voluntary $v s$ involuntary treatment); legal status (e.g., jail diversion, Not Guilty by Reasons of Insanity, Incompetent to Stand Trial, etc.); and level of court involvement (e.g., whether the court controls admission and discharge decisions, participation by parole authorities, etc.).

Despite the complexity and diversity of forensic programs, the field appears to be converging on the conclusion that ACT is ineffective or minimally effective with forensic populations. This may be premature and misguided especially in light of emerging research on the effectiveness of the forensic continuum model and correctional reentry programs, both of which combine residential rehabilitative treatment with aftercare treatment. Research should continue to evaluate the effectiveness of ACT with forensic populations. In particular, there is encouraging evidence that ACT can be more effective when it is preceded with an integrated residential rehabilitation program.

\section{REFERENCES}

[1] Dixon L. Assertive community treatment: twenty-five years of gold. Psychiatr Serv 2000; 51: 759-65.

[2] Test MA, Stein LI. Practical guidelines for the community treatment of markedly impaired patients. Commun Ment Health J 1976; 12(1): 72-82.

[3] Stein LI, Test MA. Alternative to mental hospital treatment: I. Conceptual model, treatment program, and clinical evaluation. Arch Gen Psychiatry 1980; 37(4): 392-7.

[4] The 1974 APA Achievement Award Winners. Gold Award: a community treatment program. Madison, Wisconsin: Mendota Mental Health Institute. Hosp Community Psychiatry 1974; 25: 669-72.

[5] Jennings JL. Schizophrenia and therapist involvement: changing the practice of four major psychotherapies. Psychotherapy 1987; 24(1): 58-70.

[6] Lamberti JS, Weisman RL, Faden DI. Forensic assertive community treatment: preventing incarceration of adults with severe mental illness. Psychiatr Serv 2004; 55(11): 1285-93.

[7] Stein LI, Santos AB. Assertive community treatment of persons with severe mental illness. New York: Norton 1998.
[8] Phillips SD, Burns BJ, Edgar ER, et al. Moving assertive community treatment into standard practice. Psychiatr Serv 2001; 52: 771-9.

[9] McFarlane WR. FACT: integrating family psychoeducation and assertive community treatment. Adm Policy Ment Health 1997; 25(2): 191-8.

[10] Macias C, Rodican CF, Hargreaves WA, Jones DR, Barreira PJ, Wang Q. Supported employment outcomes of a randomized controlled trial of ACT and clubhouse models. Psychiatr Serv 2006; 57: 1406-15

[11] Drake RE, Mercer-McFadden C, Mueser KT, McHugo G, Bond GR. Treatment of substance abuse in patients with severe mental illness: a review of recent research. Schizophr Bull 1998; 24: 589608 .

[12] Mueser KT, Bond GR, Drake RE, Resnick SG. Models of community care for severe mental illness: a review of research on case management. Schizophr Bull 1998; 24: 37-74.

[13] Essock SM, Drake RE, Burns BJ. A research network to evaluate assertive community treatment: introduction. Am J Orthopsychiatry 1998; 68: 176-8.

[14] Substance Abuse and Mental Health Services Administration. Cooccurring disorders: integrated dual disorders treatment: implementation resource kit. Rockville, MD, Center for Mental Health Services, 2003.

[15] Rosenheck RA, Neale MS, Leaf P, Milstein RM, Frisman LK. Multi-site experimental cost study of intensive psychiatric community care. Schizophr Bull 1995; 21: 129-40.

[16] Rosenheck RA, Neale MS. Cost-effectiveness of intensive psychiatric community care for high users of impatient services. Arch Gen Psychiatry 1998; 55: 459-66.

[17] Rosenheck RA, Neale MS. A critique of the effectiveness of assertive community treatment: in reply. Psychiatr Serv 2001; 52: 1395-6.

[18] APA/CAPP. American Psychological Association and Committee for the Advancement of Professional Practice's Task Force on Serious Mental Illness and Severe Emotional Disturbance. Catalog of clinical training opportunities: best practices for recovery and improved outcomes for people with serious mental illness 2007.

[19] Gomory T. Assertive community treatment (ACT): the case against the "best tested" evidence-based community treatment for severe mental illness. In: Kirk SA, Ed. Mental disorders in the social environment: critical perspectives. New York: Columbia University Press 2005.

[20] Solomon P, Draine J. One-year outcomes of a randomized trial of case management with seriously mentally ill clients leaving jail. Eval Rev 1995; 19: 256-73.

[21] Diamond R. Coercion and tenacious treatment in the community. In: Dennis DL, Monahan J, Eds. Coercion and aggressive community treatment. New York: Plenum Press 1996; pp. 51-72.

[22] Mosher LR, Burti, L. Community mental health. New York: Norton 1989.

[23] Gomory T. The origins of coercion in assertive community treatment: a review of early publications from the special treatment unit of Mendota State Hospital. Ethical Hum Sci Serv 2002; 4(1): 3-16.

[24] Lewin Group. Assertive community treatment literature review. Falls Church, VA: Lewin Group 2000.

[25] Coldwell CM, Bender WS. The effectiveness of assertive community treatment for homeless populations with severe mental illness: a meta-analysis. Am J Psychiatry 2007; 164(3): 393-9.

[26] Bond GR, Drake RE, Mueser KT, Latimer E. Assertive community treatment for people with severe mental illness: critical ingredients and impact on patients. Dis Manag Health Outcomes 2001; 9: 14159.

[27] Morrissey JP, Meyer PS, Cuddeback GS. Extending assertive community treatment to criminal justice settings: origins, current evidence, and future directions. Commun Ment Health J 2007; 43: 527-44.

[28] Cimino A, Jennings JL. Arkansas partnership program: an innovative continuum of care program for dually diagnosed forensic patients. Psychiatr Rehabil Skills 2002; 6: 104-14.

[29] Lamberti JS, Weisman RL. Preventing incarceration of adults with severe mental illness: Project Link. In: Landsberg G, Ed. Serving Mentally Ill Offenders. New York: Springer 2002. 
[30] Weisman RL, Lamberti JS, Price N. Integrating criminal justice, community mental healthcare, and support services for adults with severe mental disorders. Psychiatr Q 2004; 75: 71-85.

[31] Lurigio AJ, Fallon, JT, Dincin, J. Helping the mentally ill in jails adjust to community life: a description of a post-release ACT program and its clients. Int J Offender Ther Comp Criminol 2000; 44: $532-48$

[32] Gold Award. Helping mentally ill people break the cycle of jail and homelessness. The Thresholds State, County Collaborative Jail Linkage Project, Chicago. Psychiatr Serv 2001; 52(10): 1380-2.

[33] Broner N, Lattimore PK, Cowell AJ, Schlenger WE. Effects of diversion on adults with co-occurring mental illness and substance abuse: outcomes from a national multi-site study. Behav Sci Law 2004; 22(4): 519-41.

[34] Steadman HJ, Naples M. Assessing the effectiveness of jail diversion programs for persons with serious mental illness and cooccurring substance use disorders. Behav Sci Law 2005; 23: 16370.

[35] Cosden M, Ellens JK, Schnell JL, Yamini Diouf Y, Wolfe MM. Evaluation of a mental health treatment court with assertive community treatment. Behav Sci Law 2003; 21: 415-27.

[36] Solomon P, Draine J. Jail recidivism in a forensic case management program. Health Soc Work 1995; 20(3): 167-73.

[37] Loveland D, Boyle M. Intensive case management as a jail diversion program for people with a serious mental illness: a review of the literature. Int J Offender Ther Comp Criminol 2007; 51(2): 130-50.

[38] Drake RE, Morrissey J, Mueser KT. The challenge of treating forensic dual diagnosis clients: comment on "integrated treatment for jail recidivists with co-occurring psychiatric and substance use disorders." Commun Ment Health J 2006; 42(4): 427-32.

[39] Caslyn RJ, Yonker RD, Lemming MR, Morse GA, Klinkenberg WD. Impact of assertive community treatment and client characteristics on criminal justice outcomes in dual disorder homeless individuals. Crim Behav Ment Health 2005; 15(4): 23648.

[40] Allen LC, MacKenzie DL, Hickman LJ. The effectiveness of cognitive behavioral treatment for adult offenders: a methodological, quality-based review. Int J Offender Ther Comp Criminol 2001; 45: 498-514.

[41] Van Stelle KR, Moberg DP. Outcome data for MICA clients after participation in an institutional therapeutic community. J Offender Rehabil 2004; 39: 37-62.

[42] Sacks S, Sacks JY, McKendrick K, Banks S, Stommel J. Modified therapeutic community for MICA offenders. Crime outcomes. Behav Sci Law 2004; 22: 477-501.
[43] Aos S, Miller M, Drake RE. Evidence-based adult correctional programs: what works and what does not. Olympia: Washington State Institute for Public Policy 2006.

[44] Cimino A, Smith RJ. Spotlight on innovative programs: an integrated treatment approach in the provision of services to the dually diagnosed forensic client. Presentation to The GAINS Center National Conference, Las Vegas 2004.

[45] Smith RJ, Jennings JL, Cimino A. Forensic continuum of care with $\mathrm{ACT}$ for persons recovering from co-occurring disabilities: long term outcomes. Psychiatr Rehabil J (in press).

[46] Smith RJ. Personal communication: case studies provided by director of the Arkansas Partnership Program 2008.

[47] Taxman FS, Young D, Byrne JM. From prison safety to public safety: best practices in offender reentry. Washington, DC: National Institute of Justice 2003.

[48] Listwan SJ, Cullen FT, Latessa EJ. How to prevent prisoner reentry programs from failing: insights from evidence-based corrections. Fed Probat 2006; 70: 19-25.

[49] Harrison LD. The revolving prison door for drug involved offenders: challenges and opportunities. Crime Delinq 2001; 47: 462-85.

[50] McCollister KE, French MT, Prendergast ML, Wexler HK, Sacks $\mathrm{S}$, Hall EA. Is in-prison treatment enough? A cost-effectiveness analysis of prison-based treatment and aftercare services for substance-abusing offenders. Law Policy 2003; 25: 63-82.

[51] Wexler HK, DeLeon G, Thomas G, Kressel D, Peters J. The amity prison therapeutic community evaluation - reincarceration outcomes. Crim Justice Behav 1999; 26: 147-67.

[52] Knight DD, Simpson DD, Hiller ML. Three year incarceration outcomes for in-prison therapeutic community treatment in Texas. Prison J 1999; 79: 337-51.

[53] Martin SS, Butzin CA, Saum CA, Inciardi JA. Three-year outcomes of therapeutic community treatment for drug-involved offenders in Delaware: from prison to work release to aftercare. Prison J 1999; 79: 294-320.

[54] Butzin CA, Martin SS, Inciardi JA. Treatment during transition from prison to community and subsequent illicit drug use. J Subst Abuse Treat 2005; 28(4): 351-8.

[55] Simpson DD, Wexler HK, Inciardi JA, Eds. Special issue on drug treatment outcomes for correctional settings, Parts $1 \& 2$. Prison J 1999; Vol. 79.

[56] Swan S, Jennings JL. Bermuda transitional living center: a community reintegration program for substance abusing offenders that combines therapeutic community and work release principles. Presentation to the National Mental Health Conference, Unlock the mystery: Managing mental mealth from corrections to community, Indianapolis, IN, June 2008.

This is an open access article licensed under the terms of the Creative Commons Attribution Non-Commercial License (http://creativecommons.org/licenses/by$\mathrm{nc} / 3.0 /$ ) which permits unrestricted, non-commercial use, distribution and reproduction in any medium, provided the work is properly cited. 